AsCLEPIO. Revista de Historia de la Medicina y de la Ciencia

67 (1), enero-junio 2015, p076

ISSN-L:0210-4466

http://dx.doi.org/10.3989/asclepio.2015.02

DOSSIER: CIENCIA Y SABERES AGRÍCOLAS EN CONSTRUCCIÓN EN LA HISTORIA DE AMÉRICA LATINA Y EL CARIBE: AGENTES, REDES Y CÍRCUITOS (SIGLOS XVIII-XX) / AGRICULTURAL SCIENCE AND KNOWLEDGE IN CONSTRUCTION IN

\title{
DIÁLOGO DE SABERES AMBIENTALES ENTRE EUROPA-AMÉRICA. AGROECOSISTEMAS OASIANOS EN BAJA CALIFORNIA SUR S. XVIII-XX ${ }^{1}$
}

\author{
Antonio Ortega Santos \\ Departamento Historia Contemporánea. Facultad de Filosofía y Letras. Universidad de Granada \\ aortegas@ugr.es
}

Recibido: 8 agosto 2014. Aceptado: 1 febrero 2015.

Cómo citar este artículo/Citation: Ortega Santos, Antonio (2015), "Diálogo de saberes ambientales entre Europa-América. Agroecosistemas oasianos en Baja California Sur s. XVIII-XX.", Asclepio, 67 (1): p076. doi: http://dx.doi.org/10.3989/asclepio.2015.02

RESUMEN: Desde hace más de dos siglos, las Comunidades Oasianas de Baja California Sur han estado viviendo en íntima conexión con su medio ambiente. Con la llegada de los Jesuitas se produjo un intenso proceso de exterminio biocultural de los saberes sociambientales de esas comunidades, repoblando estas huertas y llanos con población -en muchos casos colonos- procedentes del sur de España-, redimensionado la identidad territorial como ranchera que gestionó los ecosistemas bajo pautas de autosuficiencia y subconsumo, dadas las fuertes constricciones socioambientales de agroecosistemas sudcalifornianos. A inicios del siglo XXI, las comunidades oasianas luchan contra la pérdida de sus saberes comunitarios, enclavados en edenes de enorme potencial biocultural, rescatando y manteniendo los cultivos traídos con la llegada de los jesuitas. Este marco nos permite describir un proceso de colonización de los ecosistemas a lo largo de los dos últimos siglos.

PALABRAS CLAVE: Pensamiento Decolonial; Patrimonio Biocultural; Historia Ambiental; Historia Rural; Agrobiodiversidad.

\section{ENVIRONMENTAL KNOWLEDGE DIALOGUE BETWEEN EUROPE AND LATIN AMERICAN. AGROECOSYSTEMS OASIENS IN BAJA CALIFORNIA SUR S. XVIII-XX}

ABSTRACT: During two centuries, Oasis Communities of Baja California had been living in a intense connection with their environment. With the arrival of Jesuits, a deep extermination of biocultural heritage and socioenvironmental knowledges of these communities, repopulating of vegetable garden and drylands with people -in many cases, settler from the south of Spain- reconstructing the territorial identity as ranchera to manage the ecosystems under pattern of self-competence and under-consumption, due to the strong environmental constraints of lower california agro-ecosystem. At the beginning of XXIth century, Oasis Communities are fighting against the loss of community heritage, embedded in Eden with enormous bio-cultural dimension, rescuing and keeping crops from Europe with the Jesuits arrival. This frame allow us to draw a colonization process of ecosystems during contemporary age.

KEY WORDS: Decolonial Thought; Biocultural Heritage; Environmental History; Rural History; Agrobiodiversity.

Copyright: () 2015 CSIC. Este es un artículo de acceso abierto distribuido bajo los términos de la licencia Creative Commons Attribution-Non Commercial (by-nc) Spain 3.0. 
INTRODUCCIÓN: BAJA CALIFORNIA SUR. GEOGRAFÍA DE UNA PAISAJE DE CONTRASTES: MAR Y ARIDEZ

Con 1,300 km de longitud, Baja California es la segunda península más larga del mundo y una de las más esbeltas (140km de ancho en promedio). Ubicada en el noroeste de México, en su mitad septentrional se localiza el estado de Baja California y en la mitad meridional el estado de Baja California Sur. La península está flanqueada en sus dos costas por vastos espacios marinos: el Golfo de California al este y el Océano Pacífico al oeste. La une al continente una pequeñísima porción de tierra que representa solamente el $4 \%$ del total del perímetro peninsular, lo que prácticamente la convierte en una isla, como bien refleja la Figura 1. Este carácter insular no sólo se debe a estar sepa- rada del macizo continental por mares de difícil navegación, sino que por tierra la separan del resto del mundo vastos y despoblados desiertos cuya travesía sigue siendo ardua y tardada.

A lo largo de su historia, este severo aislamiento impuso a sus habitantes considerables desafíos. Para la sociedad colonial implicó una extrema dificultad para establecerse, ya que no solamente demoraron en ello diecisiete décadas, sino que una vez establecidas las misiones y los pueblos, la ocupación del territorio tuvo fuertes constricciones ambientales. A la sociedad decimonónica, compuesta en su mayoría por rancheros, el aislamiento les llevó a desarrollar estrategias de adaptación a un tipo de vida casi en autarquía.

Figura 1. Península de Baja California Sur

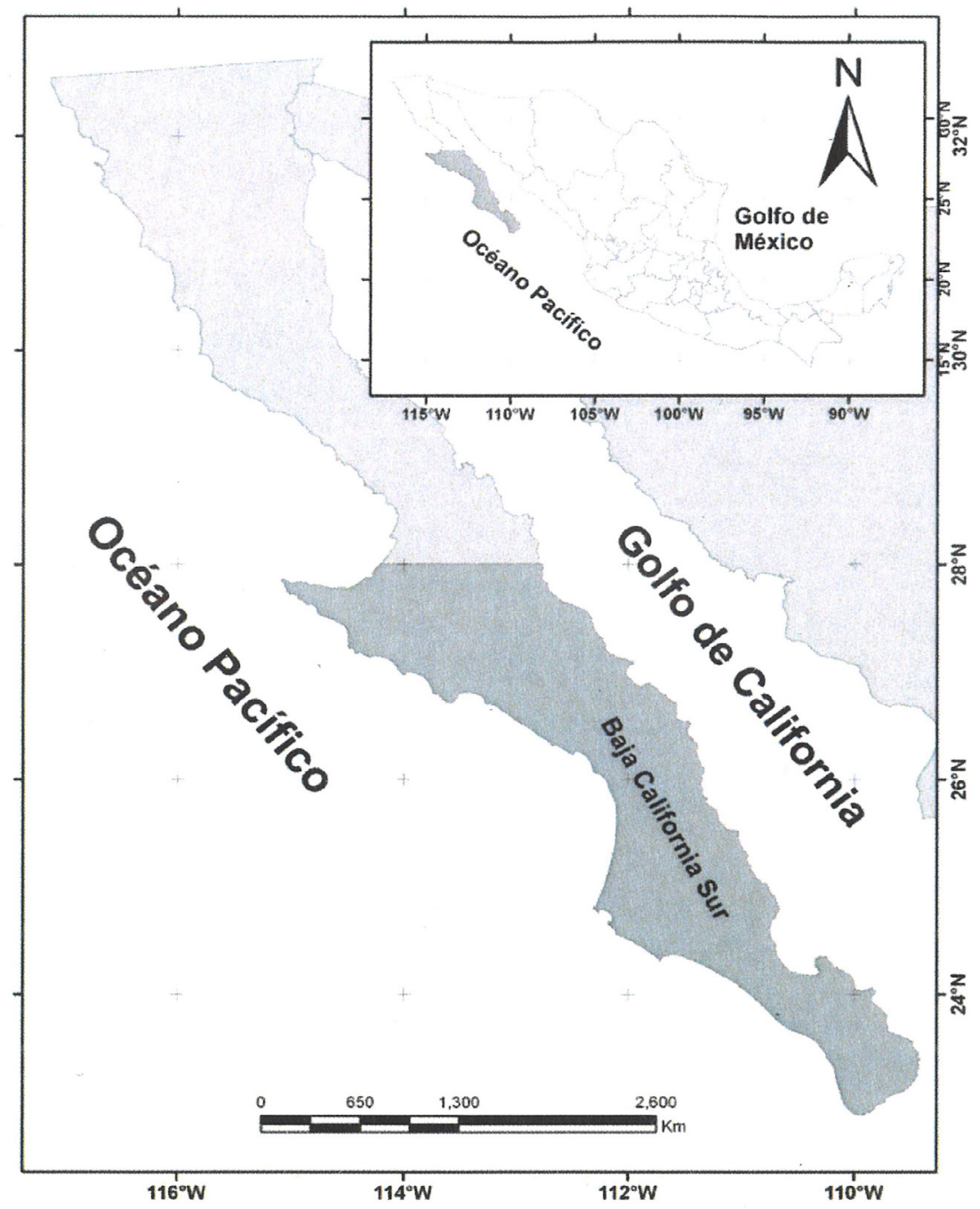


La Península de Baja California se ubica entre las latitudes $23^{\circ} \mathrm{N}$ y $32^{\circ} \mathrm{N}$, donde se localizan las grandes zonas desérticas del hemisferio norte (ver Figura 1). Por este hecho, la otra característica dominante de la geografía regional es la aridez. Ésta se manifiesta con un déficit de agua superficial y la escasez (e irregularidad) de precipitaciones. En términos generales el clima peninsular es caliente y seco, sólo hay tres pequeños ríos. En verano, las temperaturas pueden llegar hasta $50^{\circ} \mathrm{C}$ durante varios días. La región recibe en promedio menos de $250 \mathrm{~mm}$ de lluvia al año. Éstas ocurren generalmente en forma torrencial entre junio y octubre, puesto que están asociadas a la incidencia de tormentas tropicales. También se registran lluvias invernales que son menos abundantes y violentas, y se conocen en la región con el nombre local de equipatas.

En la península las limitaciones hídricas causantes de la aridez son agravadas por el aislamiento, magnificando los retos que los pobladores han enfrentado a través de originales estrategias fundamentadas sobre un denominador común: la disponibilidad permanente de fuentes agua. Sin la intervención del ser humano, en las zonas áridas ese fenómeno sólo ocurre en los humedales conocidos comúnmente como oasis. Pero con base en esa denominación común, un grupo de científicos del Centro de Investigaciones Biológicas del Noroeste (CIBNOR) (Maya et al., 1997) localizó en la península 184 oasis, de los cuales: 93\% (171) se encuentran en Baja California Sur, $48 \%$ son oasis típicos, ya que tienen aguas superficiales visibles y $52 \%$ son oasis atípicos, con arroyos de temporal. En ese estudio se describen las características bióticas y abióticas de estas ínsulas de humedad, que son espacios de excepción en el marco de una zona árida, lugar idóneo para el desarrollo de actividades humanas tales como la agricultura y la ganadería. Esos humedales son también áreas de refugio y atracción para una gran variedad de especies (endémicas o no), fungiendo también como estaciones de reabastecimiento para especies migratorias (Lluch Belda, 1997).

Otra característica geográfica de la Península de Baja California es su accidentado relieve. Longitudinalmente es recorrida por una cadena montañosa de origen volcánico formada por macizos llamados sierras, cuyas cumbres pueden fluctuar entre 1,000 y 2,000 msnm. Sus numerosas cañadas son surcadas por arroyos con cauces secos la mayor parte del año, que llegan a formar avenidas de agua durante las lluvias torrenciales, pero en los que se encuentran las pozas y los manantiales que forman los humedalesoasis. Desierto Sonorense como unidad fitogeográfica que se caracteriza por el número y la variedad de formas de vida que allí se encuentran, por la diversidad de sus comunidades vegetales, y por sus temperaturas elevadas (Shreve y Wiggins, 1964).

Se han reportado más de 2,895 especies y subespecies de plantas (Wiggins, 1980), que tienen la fisonomía de un desierto de cactáceas muy variadas que coexisten con árboles pequeños y arbustos. Por arriba de los 300 msnm y hasta los 800 , es común encontrar reminiscencias de lo que fue un bosque tropical caducifolio y, por arriba de los 1,400 msnm, se encuentra un bosque de pino-encino. La vegetación riparia que prospera en las cañadas más húmedas se caracteriza por la presencia de palmares, principalmente palma azul (Erythea armata), palma de taco (Erythea brandegeei) endémica a Baja California Sur y palma real (Washingtonia robusta); también es común encontrar palmas datileras, introducidas en el siglo XVIII por los misioneros jesuitas en los oasis bajacalifornianos. Acompañando a los palmares se distribuyen álamos (Populus spp.) y sauces (Salix spp.). En los cañones más elevados se encuentra una variedad de pequeños ambientes relictos (incluso con helechos arborescentes y orquídeas) (Wehncke et al., 2010).

A pesar de los rigores que la naturaleza bajacaliforniana ha impuesto al poblamiento humano, la región ha sido habitada constantemente desde hace más de diez mil años. Hasta finales del siglo XIX, cuando fue posible la perforación de pozos, la vida humana dependió completamente de las fuentes de agua de esos humedales y oasis, lo que les otorga un papel central en la historia ambiental bajacaliforniana, protagonizada desde la colonización jesuítica a inicios del siglo XVIII. Luego fue reemplazada por una cultura ranchera, anclada en la autosuficiencia, austeridad y aprovechamiento variado e integral de la diversidad biótica y abiótica que hunde raíces en los saberes aportados por los jesuitas junto a lo aportado por los usos indígenas en un contexto de bioregión mediterránea.

\section{NUEVAS EPISTEMOLOGÍAS PARA DECOLONIZAR LA HISTORIA SOCIOAMBIENTAL}

¿Podemos mirar con ojos no occidentales/occidentalizados, ni vinculados a los discursos colonizadores procesos socioambientales acaecidos en los dos últimos siglos en el contexto latinoamericano? Miradas que rompan con el egocentrismo epistémico, y que pongan de relieve que existieron y existen otros saberes que pueden amparar nuevas miradas futuras para la coevolución sociedades humanas y medio ambiente. 
Pero el proceso de apropiación colonial asentó y consolidó un proceso de "ordenación" de las fuerzas naturales mediante la imposición de prácticas productivas y extractivas propias de una europeización de los agroecosistemas (Escobar, 2011; Gudynas, 2011).

Como bien indica Santiago Castro-Gómez, (2011, p. 351), desde el siglo XVII, el estado colonial impreso en la huella de los Borbones, transitaba no a la búsqueda de apropiación de territorios sino también por la correcta y eficaz gestión de las poblaciones y territorios ya poseídos, mediante la ruptura simbólica y metabólica de los conocimientos y saberes de estas poblaciones.

Aníbal Quijano (1991, 1999, 2000, 2001) denota que «colonialismo» supone una relación política y económica en la que la soberanía de una nación o pueblo descansa en el poder de otra nación, lo que convierte a esta última en imperio; mientras que "colonialidad» refiere a un conjunto de patrones de poder de larga duración que emergieron con el colonialismo pero definen la cultura, las relaciones intersubjetivas, la distribución del trabajo y la producción de conocimientos más allá de los estrictos límites de las administraciones coloniales. Sobre esas diferencias, Grosfoguel (2012) apunta:

El colonialismo es más antiguo que la colonialidad

(...) Lo nuevo en el mundo moderno-colonial es que

la justificación de dicha dominación y explotación

colonial pasa por la articulación de un discurso racial acerca de la inferioridad del pueblo conquistado y la superioridad del conquistador (Grosfoguel, 2007).

Por su parte Santiago Castro-Gómez (2007, p. 79) señala que el discurso hegemónico del modelo civilizatorio se articula a través de una estructura triangular entre la «colonialidad del saber», la «colonialidad del poder», y la "colonialidad del ser». Por ello es necesario descolonizar esas tres esferas. Esta es la esencia de la crítica decolonial o perspectiva de la modernidad/colonialidad, que se ha ido conformando a partir de las críticas que desde la noción «colonialidad del poder» hizo Aníbal Quijano (1991) a la «teoría del sistema mundo moderno" propuesta antes por el sociólogo estadounidense Immanuel Wallerstein (1984, $1998,2006)$ y de forma conjunta y colaborativa en un trabajo posterior (Quijano y Wallerstein, 1992).

La crítica decolonial plantea que tras el fin del colonialismo y las administraciones coloniales se ha consolidado un sistema-mundo donde la epistemología occidental domina sobre el resto de las epistemologías. En ese sentido interesa destacar, como apunta Grosfoguel (2012) que la jerarquía epistémica del sujeto de enunciación occidental en el sistema-mundo moderno/colonial adquiere múltiples manifestaciones, de las cuales se pueden destacar las siguientes (Farrés, 2013): formación de clase global particular donde van a coexistir y organizarse una diversidad de formas de trabajo (esclavitud, semiservidumbre, trabajo asalariado, producción mercantil-simple, etc.) como fuente de producción de plusvalía mediante la venta de mercancías para obtener ganancias en el mercado mundial; una jerarquía etno/racial global que privilegia a los occidentales sobre los no-occidentales (Quijano, 1991; 2000, 2001; Mignolo, 2000b); una jerarquía ecológica global donde se privilegia el concepto de "naturaleza" occidental (donde la naturaleza es siempre pasiva, exterior a los humanos e instrumental para un fin) con todas las consecuencias nefastas para el medio ambiente/ecología planetaria y se descartan otras formas de entender el medio ambiente y la ecología (donde las personas son parte de la ecología y la «naturaleza» es un fin en sí mismo).

En cuanto a la «colonialidad del poder territorial», definida siguiendo a Mignolo (2000) como el ámbito de la intersubjetividad en que cierto grupo de gentes define qué es territorialmente correcto $y$, por lo tanto, sustentan el poder de enunciación, esta se ejerce tanto en los escenarios territoriales globales como en los locales. Esta colonialidad territorial es eficaz generando jerarquías en el territorio que tienen como apoyo genealogías de saber desde la primacía de las epistemologías occidentales.

Desde el paradigma del Imperialismo Ecológico de Crosby (1999) se auspiciaba -con amplio seguimiento historiográfico posterior - una visión de las nuevas Europas como un proceso de colonización biótico, estático, impulsivo y no procesual. Si tomamos como uno de los puntos de referencia más cercano a Dunmire (2004) la imagen de la llegada de estos frutos, árboles, cultivos, son resultado de flujos globales que circunnavegan la tierra desde siglos atrás, con un tamiz de enorme trascendencia como es el mediterráneo en el que se combinaron civilizaciones, grupos humanos y saberes híbridos que germinaron en otros mundos, en otras Europas. Este proceso es el que aquí pretendemos complejizar con una mirada decolonial, ejemplificando esos oasis un buen laboratorio para el estudio de la agrodiversidad global y en un futuro, del impacto del antropoceno en la cuasi desaparición de la especie humana a manos del cambio climático. 


\section{COLONIALIDAD DE TERRITORIOS. OASIS-HUERTAS EN BAJA CALIFORNIA SUR (MÉXICO) EN EL SIGLO XVIII}

La colonización de las tierras peninsulares de Baja California Sur se llevó a cabo diecisiete décadas después de que se realizara el Primer Auto de posesión por Hernán Cortés en 1535. Los únicos capaces de enfrentar el reto que implicaba la aridez y el aislamiento fueron los jesuitas, que en 1697 iniciaron y consolidaron el arduo proceso misional. Este proceso de colonización aplicado al territorio que se pone de manifiesto en la Figura 2 nos describe visualmente como lograron fundar 18 misiones con esfuerzos aún mayores. La principal determinante para el establecimiento de una misión fue la disponibilidad constante de agua, la que sólo hallaron en los humedales. La práctica agrícola era indispensable para alimentar a misioneros, colonos y neófitos, pero también para ayudar en el proceso de aculturación de los indígenas.

Desde su llegada a la primera fundación permanente, dedicada a la virgen de Loreto, hecha en 1697 en un paraje del golfo de California al que los indios denominaban Conchó, los misioneros y sus auxiliares no pararon de buscar sitios propicios que cumplieran con los requisitos necesarios para realizar su tarea transformadora. Tal como lo hacía ver un jesuita:

Resultaba, pues, lógico que los primeros misioneros, que se alimentaban al principio con los granos y carnes que trajeron consigo de Sonora y Sinaloa, sobre la otra costa del mar, estuviesen ansiosos de implantar la agricultura y ganadería en California para poder mantenerse en lo futuro, no sólo a sí mismos y a sus sucesores, sino también a los soldados, marineros, californios enfermos y catecúmenos (Baegert, 1989, p. 175)

Los indios que frecuentaban los parajes de la sierra de la Giganta habían tenido contacto con los extranjeros desde 1684, cuando el padre Eusebio Kino, acompañando a Isidro de Atondo y Antillón había explorado su ladera occidental (Mathes, 1965, 1970). Un largo y errático trayecto histórico de entrada al territorio sudcaliforniano que se sustentaba en los abastecimientos desde la contracosta, ante el carácter inhóspito e improductivo del nuevo lugar ocupado por el asentamiento jesuítico - no exento de un amplio apoyo financiero-. El contacto, primero colaborativo, de los nuevos pobladores con cochimíes, guaycuras y pericúas auspiciaba encontrar los aguajes de aprovisionamiento de agua en los que asentar las misiones como lugar sagrado pero también como unidad de producción, abastecimiento y consumo.
¿Cuál fue el proceso de "colonialidad de saberes» que verificó en el territorio sudcaliforniano?, ¿Cómo llegaron los cultivos "europeos» que conformaron las huertas oasianas? ¿Hasta donde llegó ese proceso? Son sólo algunas de las preguntas que vertebran este texto pero que nos permiten afirmar que la llegada/intrusión de cultivos, saberes hidráulicos y modelos agrícolas supuso una europeización del patrón territorial a largo plazo.

La manifiesta aversión de los Jesuitas para con el espacio sudcaliforniano, se sustentaba en la inviabilidad de una producción agrícola siempre deficitaria de suelos y agua, forzando la importación de bienes de la contracosta, sobre todo del Valle del Yaqui del que provenía el maíz y trigo a Baja California. Para ello se "crearon suelos», diseñaron sistemas hidráulicos compuestos por acequias, presas y diques, se importaron patrones de cultivo mediterráneos presentes en el tiempo hasta el día de hoy como acredita el último apartado de este artículo. Misiones-Huertas como estrategias de colonialidad del territorio que refleja la Figura 2, al implicar tras la ardua trayectoria histórica hasta el definitivo asentamiento- un control decisorio sobre los individuos, conocimientos y formas de actuar de las comunidades autóctonas, subsumidas en unos nuevos agroecosistemas mediterráneos.

Tomemos algunos ejemplos de este proceso. El informe enviado por el Jesuita Josep de Mora en 1704 nos evidencia este proceso de colonización del territorio sudcaliforniano para la producción agropecuaria (Venegas, 1757, p. 50):

Las fanegas de tierra que actualmente tiene, y siembra de trigo esta misión son ocho: Para maiz, tiene cinco fanegas largas de tierra, y esas estan sembradas este año, aunque regularmente se siembran solas tres, segun los años, y la gente que puede trabajar. Para chicharos, garbanzos, y frijol tiene como diez y seis almudes de tierra, atendiendo á los almudes de semilla que caben en dicha tierra: y asi han reguladas las tierras de trigo y maiz lo que se tendrá presente para quando hablemos de las tierras que no tienen agua (AGN: IC, Vol. 166, Exp1, 64r).

A la altura de 1734 en la Misión de San José de Comondú, el Jesuita José de Vicente nos muestra un patrón de cultivo más complejo, más sujeto a una diversificación productiva y adaptativa a los suelos creados y a un manejo altamente preciso y eficiente del agua como bien escaso en su origen que no en su potencialidad (citado en Venegas, 1757, p. 55): 
... Tiene un pedaso de tierra de tres a quatro almudes sembrado de caña dulce, donde coge la panocha para su gasto, y suvenir a otras necesitadas. = Una viña que consta de mil ochocientas veinte y nueve parras, distribuida en seis pedasos, quatro de ellos esta contiguos al cerro en tierra que no puede darsele mejor destino: los dos restantes estan en tierra llana pero es dificil ajustar si ocupan una, ó mas fanegas de tierra, por quanto nunca se han sembrado de otra cosa y por eso no se pone aqui el punto fixo. Tiene, ciento, y seis pies de olivos; distribuidos en dos partes, y en tierra pedregosa, situados en las faldas de los cerros. De ellos un año coge azeyte y otros no. = Ciento, quarenta y tres granados con chico, y grande, nuevos y viejos; nueve sapotes blancos; onze limones; ocho guayabos; diez naranjos con grandes, y chicos; tres palmas de dátiles; dos limas; un aguacate; un durazno; trescientas, y catorce higueras; ochocientos, y quarenta pies de platanos; y todos estos arboles frutales estan plantados en los sanjas, y ragaderas...

Esta pormenorizada descripción de un paisaje agrario, similar al que encontramos en la actualidad como manifiesta la última parte de este texto, nos evidencia una colonialidad de los saberes agrarios por parte de los colonizadores.

A partir de la fundación de la misión de Loreto en 1697, los misioneros y sus auxiliares supieron casi enseguida que los espacios al occidente y al norte de Loreto estaban poblados por numerosas bandas de grupos que eran denominados por los catecúmenos como «cochimíes» (Venegas, 1757). Habida cuenta del número importante de "rancherías», como los misioneros llamaban a las bandas de nativos, así como de la existencia de agua permanente, en 1708 se llevó a cabo la fundación de un establecimiento misional, con el nombre de San José, cerca del arroyo de Comondú «distante de Loreto treinta leguas al noroeste, y situado en el centro de las montañas, casi a igual distancia de ambos mares» (Clavijero, 1975, p. 130). Esta localización en muchos momentos fue infructuosa, forzando a la relocalización a posteriori en aras a una mayor idoneidad para los cultivos traídos de la península. Fue lo que ocurrió en Comondú: el primer sitio elegido presentó serias dificultades para las labores agrícolas. Se tomó entonces la decisión, en 1736, de mover el asentamiento unos 48 kilómetros al suroeste, hacia un paraje que había sido en un principio "pueblo de visita» de la misión de San Francisco Javier, llamado San Miguel. En 1737 la misión de San José fue movida por tercera y última ocasión al sitio, que también había sido pueblo de visita, con el nombre de San Ignacio, unos tres kilómetros corriente arriba del arroyo, bajo la categoría de pueblos de visita (Vernon, 2002, p. 56) ${ }^{2}$.
Entre 1699 y 1720 ya habían sido fundadas siete misiones más, de las cuales, San Francisco Javier, en la sierra de La Giganta, San Juan Bautista Ligüig hacia la costa del golfo de California y La Purísima Concepción, más cercana al Pacífico, además de la misión rectora de Loreto, estaban permanentemente relacionadas a través de una red de caminos que se abrió trabajosamente gracias al esfuerzo indígena bajo control y coerción de los jesuitas. Y es que la concepción que los religiosos y sus auxiliares tenían de las tierras californianas era muy pobre, tal y como lo asevera Miguel del Barco:

Puede decirse en general que su temple es seco y caliente con exceso, y que la tierra es quebrada, áspera y estéril, cubierta casi toda de tierras, pedregales y arenas inútiles, escasa de lluvias y de manantiales, y por eso poco a propósito para ganados y del todo inepta para siembras y árboles frutales si no hay agua con qué regarlos con frecuencia (Del Barco, 1980, p. 3).

Dos cultivos fueron básicos en las misiones californianas: el maíz y el trigo. El primero tuvo gran importancia para la evangelización, ya que los misioneros lo utilizaban para atraer a los indígenas y también para retenerlos en la misión mientras eran adoctrinados. Al respecto, los jesuitas, como los misioneros que les siguieron en la tarea colonizadora de la Antigua California, estaban persuadidos de que, por pocas posibilidades agrícolas que tuviera, toda misión debía ofrecer alimento a sus habitantes. Así lo establece el padre Jaime Bravo:

... Hasta ahora sólo la última misión del norte, del nombre de San Ignacio, ha podido con sumo trabajo coger anualmente el maíz que necesita, y ni le sobra ni tiene capacidad de tierra y agua más que la muy precisa para su manutención. Otra misión ninguna hay que pueda, con sólo lo que siembra y coge, mantenerse de maíz sin que necesite de mar en fuera; ni tampoco hay ninguna que haya omitido diligencia a todo costo y trabajo, como que es el principal medio para el bien de los pobres indios, los más miserables de cuantos habrá en todo el mundo ${ }^{3}$...

En San José de Comondú, la transformación de los terrenos requirió tanto de la continuidad en el abastecimiento de agua, así como por la sedimentación de los terrenos, construidos ex profeso. A pesar de ello, con el tiempo la misión logró buenas cosechas, como la reportada en 1755, que constaba de 900 fanegas de trigo espiguín y casi 500 de maíz. De sus viñas y olivares se llegaron a obtener más de 70 botijas de vino y algunas de aceite ${ }^{4}$. 
Por otro lado, el ganado llegó con el tiempo a ser uno de los recursos más importantes de la Antigua California, pues a los pocos años de la fundación de Loreto, evento para el cual el padre Salvatierra había llevado "un caballo, diez carneros, cuatro cabras con su macho y cuatro lechoncitos" ${ }^{5}$, el ganado menor ya alcanzaba el millar de efectivos. Llegó un momento en el que el ganado caprino se hizo montaraz, llamado "cimarrón", y superó con mucho en cantidad al que se conservó bajo el control de los auxiliares misionales (Del Río, 1974, p. 250-251). En el inventario que dejó el padre Francisco Ynama cuando fue expulsado de su misión junto con sus compañeros jesuitas en 1767 se establece para Comondú la posesión de 198, entre caballos, yeguas y potros; 69 mulas, 24 becerros, 22 burros, 840 ovejas de lana y 235 de pelo 6 .

Con el propósito de modificar la política de exclusividad en la toma de decisiones que habían tenido los ignacianos, la corona española determinó que los bienes y las tierras misionales fueran administrados por la milicia. No pasó mucho tiempo sin que se descubriera lo desacertado de la medida, puesto que las tierras dejaron de cultivarse, el ganado se sacrificó sin control y se desatendieron todos los trabajos de conservación que tanto preocupaban a los antiguos fundadores del sistema misional. Entonces se rectificó y fueron los misioneros, ahora de la Orden de San Francisco, quienes se hicieron cargo de esos aspectos. Cuando a su vez los franciscanos dejaron los establecimientos para ir a las poblaciones de la Alta California, los dominicos pasaron a hacerse cargo de las ya exiguas y debilitadas poblaciones de la península. Hacia la época en la que habían de retirarse de las misiones de la Antigua California, tenemos un reporte del franciscano Juan Ramos de Lora, quien describe así las posesiones de la misión de Comondú:

\footnotetext{
... No tiene esta misión rancho de ganado mayor vacuno por no haber en todo el aquel territorio paraje en que poder situarlo, por lo escabroso de él; pero tiene los bueyes necesarios para cultivar las tierras y algunas pocas vacas para cría que mantienen la misión. Tiene también las mulas y los caballos necesarios para el giro de la misión y matanzas de ganado. También tiene dos ranchos o pastorías para crías de ganado menor, de que tiene de una y otra especie, y mayormente de lana, un número competente de cabezas. Las siembras que aquí se hacen son bastantes para poder mantener sin escasez a los indios y aun, cuando se logran bien, socorrer a otras misiones más pobres... (Del Río, 1974, p 26-27).
}

Este estado de abandono de las huertas misionales no oscurece que el trabajo de apropiación por gente de la milicia, agricultores emigrados de diversos lugares de México y la Península Ibérica a lo largo del siglo XVIII, de muchas de las huertas asociadas a la ganadería extensiva bajo el nombre de ranchería - retomado de la denominación que los jesuitas aplicaron a las formas indígenas de ocupación del territorio- fueran y han sido el sostén de un patrón de cultivos que perduró hasta hoy día en los oasis sudcalifornianos. A esta continuidad dedicamos la última parte de este artículo.

\section{PALMERAS, OLIVOS, VIDES E HIGUERAS. MIRADAS DESDE EL PRESENTE A LOS FLUJOS DE AGRODIVERSI- DAD EN LOS TERRITORIOS OASIANOS}

Esta transformación biótica de alto impacto sobre la estructura original de los oasis nos ha dejado un rastro hasta el tiempo presente. En los trabajos de campo desarrollado en los últimos años hemos atendido a la dinámica histórica de la agricultura sudcaliforniana, su inserción en mercados globales-regionales, la conversión de sus patrones de cultivo hacia lógicas de intercambio comercial generando como secuela el abandono de la agricultura de subsistencia y la pérdida de la centralidad de los oasis huertas en el sistema agrario, al amparo de la creación de nuevas áreas de expansión agrícola orientadas a lógicas mercantiles, sustentadas bajo el abastecimiento de agua extraída de los acuíferos por bombeo gracias a tracción de fuerza animal y cada vez más dependiente de combustibles fósiles (Lassépas, 1859; Ortega Santos, 2011, 2013).

En este contexto general, las huertas ubicadas en los oasis funcionan con base en un sistema de agricultura estratificada, donde el dosel es ocupado por palmas datileras y de taco (Washingontias) y por debajo de éste se encuentran plantaciones de olivos, cítricos, vides de uva misionera y otros árboles frutales perennes, intercalados con espacios abiertos donde se siembran cultivos anuales. Estos incluyen variedades históricas como habas y chícharos, pero también cultivos comerciales tales como cebollas, chiles y ajo. Mientras que la extensión de las huertas y de las acequias se ha transformado con el tiempo, muchos de estos campos contienen variedades antiguas que han sido cultivadas por varias generaciones de agricultores: primero los neófitos indígenas, luego los rancheros que les siguieron y actualmente las familias de los residentes de los oasis que atienden los campos. 
Los rancheros que se hicieron cargo de la gestión de los oasis después de la expulsión de los jesuitas, construyeron su cultura con base en los conocimientos de los indígenas sobre la flora local, las prácticas agrícolas introducidas en los oasis e incorporaron a éstas nuevas especies en las huertas de los oasis y generando una cultura identitaria territorial oasiana (Cariño, 1996; Cariño y Castrorena, 2007, Cariño, 2011, 2013).

Los cultivos perennes que llegaron a la Península siguieron caminos largos y tortuosos para llegar a estos "destinos finales". Los cultivos como los cítricos y el taro, cruzaron el continente asiático o viajaron por vía marítima a España (Ramón Laca, 2003; Dunmire, 2004). Las palmas datileras, granados, olivos, higos y uvas, vinieron de la Península Arábiga, África del Norte y de la región Mediterránea; fueron transportados a España por los musulmanes (Nabhan, 2012). Estas especies cruzaron el océano Atlántico como semillas, esquejes en vivo o plantas, hasta llegar a la costa este de México. Algunas especies, como el coco y el mango llegaron directamente a México por el Océano Pacífico, en los Galeones de Manila (Mukherjee, 1953; Zizumbo-Villarreal, 1996). Otras especies nativas de las
Américas, como la chirimoya, granadilla, agave, nopal, nopalillo, guayaba, papaya y zapote, fueron transportados a través del Golfo de California hasta los oasis de la Baja California.

Los estudios realizados en los oasis agrícolas de Egipto, Omán y Baja California muestran que los oasis, que contienen colecciones de especies complejas, son sitios únicos para la conservación in-situ formal e informal, tanto de los cultivos como de los conocimientos tradicionales (Altieri y Merrick, 1987; Geubauer et al., 2007; Nabhan, 2007; Nabhan et al., 2010). Asimismo, la diversidad agrícola y el conocimiento tradicional que existe en estos sistemas activos son recursos para el futuro de la humanidad y para el de los sistemas naturales (Hammer y Teklu, 2008).

Para conocer los patrones de persistencia de la agrobiodiversidad, se pueden tomar (Nabhan et al, 1982, Nabhan et al, 2010; Rouston 2012) doce de los quince oasis agrícolas habitados por los jesuitas en 1768, año en el que fueron expulsados de la península de Baja California (ver Figura 2).

Figura 2.

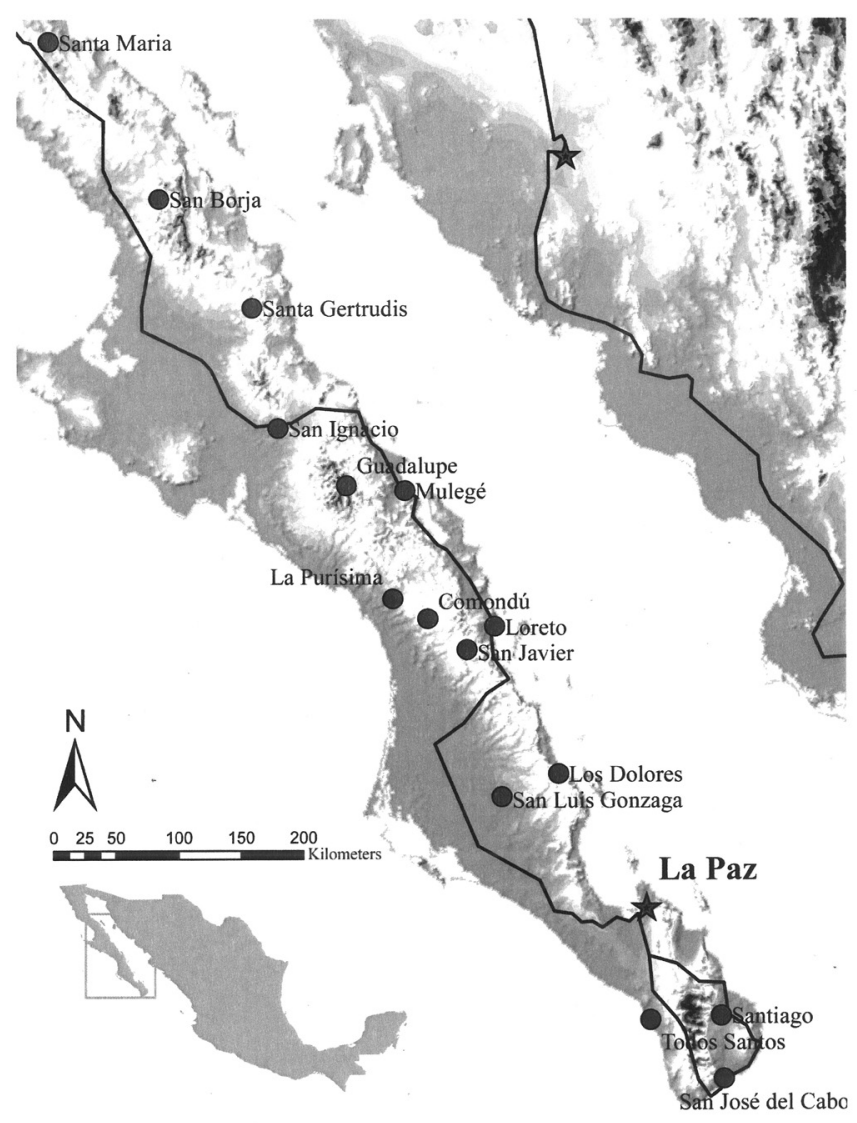


Los doce oasis aparecen enumerados en orden geográfico de norte a sur son: San Francisco Borja de Adac (SB), Santa Gertrudis (SG), San Ignacio Kadakaamán (SI), Nuestra Señora de Guadalupe (GU), Santa Rosalía de Mulegé (MU), La Purísima Concepción (LP), San José
/ San Miguel de Comondú (CU), San Francisco Javier de Viggé Biaundó (SJ), San Luis Gonzaga Chiriyaqui (SLG), Nuestra Señora de los Dolores (LD), Santa Rosa de las Palmas/Todos Santos (TS) y Santiago de los Coras (SC), cuya posición aparece reflejada en la Tabla 1.

Tabla 1. Datos de los oasis y las misiones jesuitas de Baja California

\begin{tabular}{|c|c|c|c|c|c|c|}
\hline Oasis & Coordenadas & Altitud & Temp. & Precipitación Anual & Área en cultivo & Pob. 2010 \\
\hline SB & N28 44.657 W113 45.255 & $400 m$ & - & - & $6.29 \mathrm{ha}$ & 11 \\
\hline SG & N28 03.081 W113 05.097 & $400 m$ & $0 \circ \mathrm{C}-42 \circ \mathrm{C}$ & $109 \mathrm{~mm}$ & 9.47ha & 300 \\
\hline SI & N27 17.024 W112 53.912 & $120 m$ & $-1 \stackrel{\circ}{ } \mathrm{C}-45 \div \mathrm{C}$ & $145 \mathrm{~mm}$ & $25.68 \mathrm{ha}$ & 667 \\
\hline GU & N26 55.153 W112 24.353 & $700 m$ & $-5.5-46 \div \mathrm{C}$ & $239 \mathrm{~mm}$ & $0.50 \mathrm{ha}$ & 5 \\
\hline $\mathrm{MU}$ & N26 53.118 W111 59.159 & $8 m$ & $-1.5-45 \circ \mathrm{C}$ & $97 \mathrm{~mm}$ & 6.64ha & 3,821 \\
\hline LP & N26 11.422 W112 04.371 & $100 \mathrm{~m}$ & $0 \circ \mathrm{C}-45 \div \mathrm{C}$ & $113 \mathrm{~mm}$ & 75.93ha & 433 \\
\hline $\mathrm{CU}$ & N26 03.583 W111 49.330 & $280 m$ & 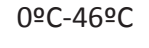 & $230 \mathrm{~mm}$ & 65.60ha & 257 \\
\hline SJ & N25 51.652 W111 32.521 & $420 m$ & 1 으- $47 \circ \mathrm{C}$ & $255 \mathrm{~mm}$ & 17.01ha & 131 \\
\hline LD & N25 03.333 W110 53.071 & $55 \mathrm{~m}$ & $19 \mathrm{C}-45 \div \mathrm{C}$ & $249 \mathrm{~mm}$ & 13.97ha & 5 \\
\hline SLG & N24 54.490 W111 17.451 & $160 m$ & $0 \div \mathrm{C}-46 \div \mathrm{C}$ & $191 \mathrm{~mm}$ & 4.60ha & 37 \\
\hline TS & N23 26.991 W110 13.531 & $41 \mathrm{~m}$ & $3 \circ \mathrm{C}-42^{\circ} \mathrm{C}$ & $144 \mathrm{~mm}$ & 153.15ha & 5148 \\
\hline SC & N23 28.540 W109 43.041 & $120 \mathrm{~m}$ & $-2 \circ \mathrm{C}-44 \stackrel{\circ}{ } \mathrm{C}$ & $308 \mathrm{~mm}$ & 45.80ha & 752 \\
\hline
\end{tabular}

Fuente: Rouston 201, 2013, calculado de CONAGUA 2011; censo de INEGI 2010.

El principal propósito de la huerta es la producción de alimentos para el consumo interno y también pueden proveer forraje para el ganado, los agricultores cultivan, cosechan y transportan la cosecha y el forraje para los animales, o bien conducen a los animales a la huerta para que coman directamente el rastrojo entre los periodos de cultivo.

Para determinar el alcance de la introducción de los cultivos originales a la Península durante la época jesuita, se pueden rastrear información en los archivos del Museo del Estado de Arizona, el Archivo General de la Nación (AGN), en el Distrito Federal, y el Archivo Histórico de Baja California Sur, Pablo L. Martínez (AHPLM), en La Paz. Los primeros inventarios completos de las especies, las descripciones de la superficie agrícola y de los cultivos anuales y perennes de las misiones jesuíticas, se encuentran en una serie de registros de los misioneros dominicos. La mayoría de los frutales registrados en estos inventarios eran ya árboles maduros, lo que significa que fueron plantados durante la administración de los jesuitas en la Península, lo que verifica su papel pionero y fundamental en la introducción de técnicas agrícolas y cultivos en las misiones. Este inventariado de la llegada de los cultivos de la mano misional aparece precisado en la Tabla 2.

Se pueden utilizar registros históricos, escritos y dibujos de los misioneros jesuitas Miguel Del Barco (1980) y Juan Jacobo Baegert (1989), considerándoles como fuentes primarias - fragmentarias - para los inventarios históricos de especies agrícolas y prácticas introducidas durante la época de su trabajo misional. Los escritos de Francisco Javier Clavijero (1975), que escribió en ese mismo período, también dan información acerca de la agricultura de las misiones de Baja California, aunque este misionero nunca visitó la Península y sus obras proveen solamente una descripción parcial. Ya en la época contemporánea, Harry Crosby (1994) y Vernon (2002) ofrecen la colección más completa sobre datos agrícolas legados en los escritos de los misioneros jesuitas, así como descripciones de la agricultura en las misiones hacia finales del siglo XX. 
Tabla 2. Cultivos introducidos antes de 1774 según registros misioneros jesuitas, franciscanos y dominicos

\begin{tabular}{|c|c|c|}
\hline Nombre de Cultivo & Misión & Fuente \\
\hline Aguacate & La Purísima, San Jose de Comondú & De Mora et al. 1774 \\
\hline Caña de azucar & $\begin{array}{l}\text { Todos Santos, San Ignacio, San Jose de } \\
\text { Comondú }\end{array}$ & De Mora et al. 1774; Crosby 1994 \\
\hline Chirimoya & San Miguel de Comondú, San Javier & De Mora et al. 1774 \\
\hline Cidra & La Purísima & De Mora et al. 1774 \\
\hline Coco & Loreto & Zizumbo-Villareal 1996; Crosby 1994 \\
\hline Dátil, palma & $\begin{array}{l}\text { Loreto, La Purísima, San Miguel de } \\
\text { Comondú, San Javier }\end{array}$ & De Mora et al. 1774; Aschmann 1957 \\
\hline Durazno & $\begin{array}{l}\text { La Purísima, Santa Gertrudis, San Jose } \\
\text { de Comondú }\end{array}$ & De Mora et al. 1774; Del Barco 1980 \\
\hline Granada china, granadilla & Santiago? & Del Barco 1980 \\
\hline Granado & $\begin{array}{l}\text { Loreto, Santa Gertrudis, San Jose de } \\
\text { Comondú, San Javier, Guadalupe, San } \\
\text { Ignacio, Todos Santos, San Borja }\end{array}$ & $\begin{array}{l}\text { De Mora et al. 1774; Crosby 1994; Del } \\
\text { Barco } 1980\end{array}$ \\
\hline Guayabo & La Purísima & De Mora et al. 1774 \\
\hline Higo & $\begin{array}{l}\text { Loreto, Santa Gertrudis, Todos Santos, } \\
\text { San Jose de Comondú, San Javier, } \\
\text { Guadalupe, San Ignacio, San Borja, } \\
\text { Santa Maria }\end{array}$ & $\begin{array}{l}\text { De Mora et al. 1774; Crosby 1994; Del } \\
\text { Barco } 1980\end{array}$ \\
\hline Lima & La Purísima, San Jose de Comondú & De Mora et al. 1774 \\
\hline Limón & $\begin{array}{l}\text { La Purísima, San Jose de Comondú, } \\
\text { San Javier, San Ignacio }\end{array}$ & $\begin{array}{l}\text { De Mora 1774; Crosby 1994; Del } \\
\text { Barco } 1980\end{array}$ \\
\hline Maguey & Santiago & Del Barco 1980 \\
\hline Naranja, naranjo & $\begin{array}{l}\text { La Purísima, Todos Santos, San Miguel } \\
\text { de Comondú and San Javier }\end{array}$ & $\begin{array}{l}\text { De Mora et al. 1774, Crosby 1994; Del } \\
\text { Barco } 1980\end{array}$ \\
\hline Nopal, tuna & La Purísima, San Javier & Del Barco 1980 \\
\hline Olivo, acietuna & $\begin{array}{l}\text { La Purísima, Santa Gertrudis, San Jose } \\
\text { de Comondú, San Javier, Guadalupe, } \\
\text { San Ignacio }\end{array}$ & $\begin{array}{l}\text { De Mora et al. 1774; Crosby 1994; Del } \\
\text { Barco } 1980\end{array}$ \\
\hline Plátano & San Jose de Comondú, San Javier & $\begin{array}{l}\text { De Mora et al. 1774; Crosby 1994; Del } \\
\text { Barco } 1980\end{array}$ \\
\hline Tamarindo & Loreto & De Mora et al. 1774 \\
\hline Uva, parra, zepa, серa & $\begin{array}{l}\text { La Purísima, Santa Gertrudis, San Jose } \\
\text { de Comondú, San Javier, Guadalupe, } \\
\text { San Ignacio, Todos Santos, San Borja, } \\
\text { Santa Maria, San Jose del Cabo }\end{array}$ & $\begin{array}{l}\text { De Mora et al. 1774; Crosby 1994; Del } \\
\text { Barco } 1980\end{array}$ \\
\hline Zapote (amarillo) & $\begin{array}{l}\text { La Purísima, San Jose de Comondú, } \\
\text { San Javier }\end{array}$ & De Mora et al. 1774 \\
\hline
\end{tabular}

Fuente: Rouston, 2013.

Los primeros escritos originales sobre inventarios y descripciones que se incluyen todas las misiones de Baja California, fueron realizados por el misionero franciscano Francisco Palou en 1772. Estos escritos fueron recogidos y traducidos por Engelhardt (1908) y describen el estado de los campos después de la expulsión de los jesuitas. Los cultivos introducidos por los misioneros jesuitas, como se ha señalado por estos autores incluyen uvas, higos, granadas, aceitunas, dátiles, limas, limones, naranjas y plátanos, como 
cultivos perennes, y trigo, maíz, cebada, habas, garbanzos, arroz, algodón, sandías, melones, calabazas, cebollas, remolacha, ajo, camote, tomate, lechuga, rábanos y pimientos, en cuanto a los cultivos anuales. Los inventarios cuantitativos más completos son los del dominico Vicente de Mora (1774) y registran 21 especies de cultivos perennes en las huertas de las misiones que completan un panorama de cultivos destinados a uso agroalimentario muy complejo que se refleja en la Tabla 3.

Tabla 3. Total especies de cultivos perennes alimenticios en los oasis-huertas

\begin{tabular}{|c|c|c|c|}
\hline Nombre Español & Nombre Inglés & Nombre científico & Familia \\
\hline Ackee & Ackee & Blighia sapida & Sapindaceae \\
\hline Arbol de pan & Breadfruit & Artocarpus altilis & Moraceae \\
\hline Aguacate & Avocado & Persea americana & Lauraceae \\
\hline Anona & $\begin{array}{l}\text { Annona: custard apple, } \\
\text { cherimoya, anona }\end{array}$ & Annona reticulata & Annonaceae \\
\hline Anona & Annona: sugar apple & Annona squamosa & Annonaceae \\
\hline Anona, guanabana & Annona: soursop & Annona muricata & Annonaceae \\
\hline Cacao & Cacao & Theobroma cacao & Malvaceae \\
\hline Café & Coffee & Coffea arabica & Rubiaceae \\
\hline Caña de azúcar & Sugar cane & Saccharum officinarum & Poaceae \\
\hline Canela & Cinnamon & Cinnamomum verum & Lauraceae \\
\hline Capulín o cereza & Cherry, native & Prunus serotina subsp. Virens & Rosaceae \\
\hline Carambola & Star fruit & Averrhoa carambola & Oxalidaceae \\
\hline Castaña de cajú & Cashew & Anacardium occidentale & Anacardiaceae \\
\hline Cebollín & Chive & Allium schoenoprasum & Amaryllidaceae \\
\hline Cereza & Cherry & Prunus avium & Rosaceae \\
\hline Cereza braziliano & $\begin{array}{l}\text { Cherry, tropical (Brazilian, } \\
\text { Surinam) }\end{array}$ & Eugenia uniflora & Myrtaceae \\
\hline Chabacano & Plum & Prunus domestica & Rosaceae \\
\hline $\begin{array}{l}\text { Chabacano, albaricoque, } \\
\text { alberichigo }\end{array}$ & Apricot & Prunus armeniaca & Rosaceae \\
\hline Chico zapote & Sapodilla & Manilkara zapota & Sapotaceae \\
\hline Chiltepín & Chiltepín & Capsicum annuum & Solanaceae \\
\hline Chirimoya & $\begin{array}{l}\text { Annona: custard apple, } \\
\text { cherimoya }\end{array}$ & Annona cherimola & Annonaceae \\
\hline Cidra & Citrus: citron & Citrus medica & Rutaceae \\
\hline Ciruela anaranjada & $\begin{array}{l}\text { Plum, Spanish, yellow } \\
\text { mombin }\end{array}$ & Spondias mombin & Anacardiaceae \\
\hline Ciruela roja/amarilla & Plum, Spanish, red mombin & Spondias purpurea & Anacardiaceae \\
\hline Coco & Coconut & Cocos nucifera & Arecaceae \\
\hline Dátil & Date palm & Phoenix dactylifera & Arecaceae \\
\hline Durazno & Peach & Prunus persica & Rosaceae \\
\hline Esparragos & Asparagus & Asparagus officinalis & Asparagaceae \\
\hline Granada & Pomegranate & Punica granatum & Lythraceae \\
\hline Granadilla & Passion fruit & Passiflora ligularis & Passifloraceae \\
\hline Guamúchil & Guamúchil & Pithecellobium dulce & Fabaceae \\
\hline Guayaba & Guava & Psidium guajava & Myrtaceae \\
\hline
\end{tabular}




\begin{tabular}{|c|c|c|c|}
\hline Nombre Español & Nombre Inglés & Nombre científico & Familia \\
\hline Guayaba de fresa & Guava, strawberry & Psidium littorale & Myrtaceae \\
\hline Guayabo de piña & Guava, pineapple & Acca sellowiana & Myrtaceae \\
\hline Higo & Fig & Ficus carica & Moraceae \\
\hline Jamaica & Hibiscus, sorrel & Hibiscus sabdariffa & Malvaceae \\
\hline Jinjibra & Ginger & Zingiber officinale & Zingiberaceae \\
\hline Jujube & Jujube & Ziziphus jujuba & Rhamnaceae \\
\hline Lima dulce chichona & Citrus: lime sweet & Citrus limettioides & Rutaceae \\
\hline Limón & Citrus: lime sour (small) & Citrus $\times$ aurantifolia & Rutaceae \\
\hline Limón Americana & Citrus: lime sour (large) & Citrus limon & Rutaceae \\
\hline Limón base de injertos & Citrus: lemon rough & Citrus jambhiri & Rutaceae \\
\hline Limón real & Citrus: lemon sweet & Citrus híbrido & Rutaceae \\
\hline Litchi & Lychee & Litchi chinensis & Sapindaceae \\
\hline Macademia & Macadamia nut & Macadamia integrifolia & Proteaceae \\
\hline Maguey, mescal & Century plant & Agave spp. & Asparagaceae \\
\hline Mamey & Mamey sapote & Pouteria sapota & Sapotaceae \\
\hline Mandarina & Citrus: mandarin & Citrus reticulata & Rutaceae \\
\hline Mango & Mango & Mangifera indica & Anacardiaceae \\
\hline Mangostin & Mangosteen & Garcinia mangostana & Clusiaceae \\
\hline Manzano & Apple & Malus $\times$ domestica & Rosaceae \\
\hline Membrillo & Quince & Cydonia oblonga & Rosaceae \\
\hline Mora blanca & Mulberry, white & Morus alba & Moraceae \\
\hline Mora negra & Mulberry, black & Morus nigra & Moraceae \\
\hline Mora roja & Mulberry, red & Morus rubra & Moraceae \\
\hline Mora, zarsamora & Blackberry & Rubus fruticosus & Rosaceae \\
\hline Moringa & Moringa & Moringa oleifera & Moringaceae \\
\hline Naranja amarga & Citrus: orange sour & Citrus aurantium & Rutaceae \\
\hline Naranja china & Kumquat & Fortunella margarita & Rutaceae \\
\hline Naranja dulce & Citrus: orange sweet & Citrus sinensis & Rutaceae \\
\hline Naranja lima & Citrus: lime-orange & Citrus sp. & Rutaceae \\
\hline Níspero & Loquat & Eriobotrya japonica & Rosaceae \\
\hline Nogal & Walnut & Juglans regia & Juglandaceae \\
\hline Nopal, tuna & Prickly pear & Opuntia ficus-indica & Cactaceae \\
\hline Nopalillo & Prickly pear, false & Nopalea cochenillifera & Cactaceae \\
\hline Olivo misionero & Olive & Olea europaea & Oleaceae \\
\hline Papaya & Papaya & Carica papaya & Caricaceae \\
\hline Pecan & Pecan & Carya illinoinensis & Juglandaceae \\
\hline Pera & Pear & Pyrus communis & Rosaceae \\
\hline Pimienta & Allspice & Pimenta dioica & Myrtaceae \\
\hline Piña & Pineapple & Ananas comosus & Bromeliaceae \\
\hline Plátano & Banana, plantain & Musa $\times$ paradisiaca & Musaceae \\
\hline Pomarosa & Clove & Syzygium aromaticum & Myrtaceae \\
\hline
\end{tabular}




\begin{tabular}{|l|l|l|l|}
\hline Nombre Español & Nombre Inglés & Nombre científico & Familia \\
\hline Pomelo/toronja & Citrus: pummelo & Citrus maxima & Rutaceae \\
\hline Romero & Rosemary & Rosmarinus officinalis & Lamiaceae \\
\hline Ruda & Rue & Ruta graveolens & Rutaceae \\
\hline Tamarindo & Tamarind & Tamarindus indica & Fabaceae \\
\hline Tanjerina, naranjito & Citrus: calamondin & xCitrofortunella microcarpa & Rutaceae \\
\hline Té limón & Lemon grass & Cymbopogon citratus & Poaceae \\
\hline Tepeguaje & Tepeguaje & Leucaena leucocephala & Fabaceae \\
\hline Toronja & Citrus: grapefruit & Citrus paradisi & Rutaceae \\
\hline uva misionera & Grape, mission & Vitis vinifera & Vitaceae \\
\hline Uvalma & Uvalama & Bumelia peninsularis & Sapotaceae \\
\hline Vainilla & Vanilla & Vanilla planifolia & Orchidaceae \\
\hline Yaca & Jackfruit & Artocarpus heterophyllus & Moraceae \\
\hline Yerbabuena & Spearmint & Mentha spicata & Lamiaceae \\
\hline Yuca & Yuca/cassava & Manihot esculenta & Euphorbiaceae \\
\hline Zapote amarillo & Sapote: white/yellow & Casimiroa edulis & Rutaceae \\
\hline Zapote negro/prieto & Sapote: black & Diospyros digyna & Ebenaceae \\
\hline
\end{tabular}

Fuente: Rouston, 2013.

En el Oasis de Los Comondú se registran 241 huertas oasis, con un total de 89 especies de cultivos perennes, pertenecientes a 74 géneros y 36 familias. Todas las 21 especies misionales observadas en los inventarios de 1774 fueron documentadas en investigaciones en campo en 2010 y 2011 (Rouston, 2012) aunque éstas no siempre se asocian con los mismos oasis.

Los géneros con más especies representados fueron Citrus (13 especies diferentes más los híbridos), Prunus (5 especies), Annona (4 especies), y Morus (3 especies). Entre las familias, Rutaceae (16 géneros), Rosaceae (10 géneros), Moraceae ( 6 géneros), Anacardiaceae (4 géneros), y Anonaceae (4 géneros) tuvieron el mayor número de géneros representados. Sólo tres especies fueron encontradas en los doce oasis: Naranja dulce (Citrus sinensis L. (Osbeck)), palma datilera (Phoenix dactylifera L.) y guayaba (Psidium guajava L.). Ocho especies se encontraron en 11 de los 12 oasis: las tres anteriormente mencionados y limón (Citrus $x$ aurantiifolia (Christm.) Swingle), higo (Ficus carica L.), mango (Mangifera indica L.), granada (Punica granatum L.) y uva (Vitis vinifera L.). Las siguientes especies más frecuentes (presentes en 10 de los 12 oasis) fueron papaya (Carica papaya L.), lima dulce chichona (Ci- trus limettioides Tanaka), plátano (Musa $\times$ paradisiaca L.), olivo (Olea europaea L.), y nopal (Opuntia ficus-indica (L.) Mill.). Esta última especie es un poco más problemática, ya que algunas de las plantas eran claramente Opuntia $\times$ ficus-indica o tal vez una especie de Opuntia distinta. Casi un tercio (31 spp.) de las especies en total fueron documentadas en uno de los doce oasis.

Todos Santos fue el oasis que tuvo el mayor número de especies de cultivos perennes alimentarios (79) y de familias (35) también. Santiago de los Coras, igualmente en el sur de la Península tuvo el segundo mayor número de especies (48) y familias (24). Todos Santos y Santiago tuvieron el mayor número de especies misionales (19/21). San Ignacio tenía 18 especies misiónales, San Javier 17, y Mulegé y Santa Gertrudis 16 de las 21 especies misiónales registradas en total. Todos los oasis tienen especies perennes de cultivos provenientes de la época misional, y todos tenían más de 10 especies misionales con excepción de San Luis Gonzaga, que con sólo 5, presentó el menor número de estas especies. Este panorama de las especies perennes y su presencia en los espacios oasianos, estudiados en la singularidad de cada uno, se pone de manifiesto en la Tabla 4. 
Tabla 4. Presencia/Ausencia de las especies de cultivos perennes

\begin{tabular}{|c|c|c|c|c|c|c|c|c|c|c|c|c|}
\hline Oasis Código & SB & SG & SI & GU & MU & LP & CU & SJ & LD & SLG & TS & SC \\
\hline Ackee & & & & & & & & & & & $x$ & \\
\hline Arbol de pan & & & & & & & & & & & $x$ & \\
\hline Aguacate & $x$ & $x$ & $x$ & & & & $x$ & $x$ & $x$ & & $x$ & $x$ \\
\hline Anona & & & & & & & $x$ & & $x$ & & $x$ & $x$ \\
\hline Anona & & & & & & & & & & & $x$ & $x$ \\
\hline Anona, guanabana & & & & & & & & & & & $x$ & $x$ \\
\hline Cacao & & & & & & & & & & & $x$ & \\
\hline Café & & & & & & & & & & & $x$ & $x$ \\
\hline Caña de azúcar & & & $x$ & & & & $x$ & $x$ & & & $x$ & $x$ \\
\hline Canela & & & & & & & & & & & $x$ & \\
\hline Capulín o cereza & & & & & & & & & & & $x$ & \\
\hline Carambola & & & & & & & & & & & $x$ & \\
\hline Castaña de cajú & & & & & & & & & & & $x$ & \\
\hline Cebollín & & & & & & $x$ & & & & & $x$ & \\
\hline Cereza & & & $x$ & & & & & & & & $x$ & \\
\hline Cereza braziliano & & & & & & & & & & & $x$ & $x$ \\
\hline Chabacano & & & & & $x$ & & & & & & $x$ & $x$ \\
\hline $\begin{array}{l}\text { Chabacano, albarico- } \\
\text { que, alberichigo }\end{array}$ & & $x$ & & & & & & & & & & \\
\hline Chico sapote & & & & & $x$ & & $x$ & & & & $x$ & \\
\hline Chiltepín & & & $x$ & & $x$ & $x$ & $x$ & $x$ & & & $x$ & $x$ \\
\hline Chirimoya & & & & & & & $x$ & & & & & \\
\hline Cidra & & $x$ & $x$ & & $x$ & & $x$ & $x$ & $x$ & & $x$ & $x$ \\
\hline Ciruela anaranjada & & & & & & & $x$ & & & & & $x$ \\
\hline Ciruela roja/amarilla & & & & & $x$ & $x$ & $x$ & $x$ & $x$ & & $x$ & $x$ \\
\hline Coco & & & $x$ & & $x$ & & $x$ & & $x$ & & $x$ & $x$ \\
\hline Dátil & $x$ & $x$ & $x$ & $x$ & $x$ & $x$ & $x$ & $x$ & $x$ & $x$ & $x$ & $x$ \\
\hline Durazno & $x$ & $x$ & $x$ & & $x$ & & $x$ & $x$ & $x$ & & $x$ & $x$ \\
\hline Esparragos & & & & & & & & & & & $x$ & \\
\hline Granada & $x$ & $x$ & $x$ & $x$ & $x$ & $x$ & $x$ & $x$ & $x$ & & $x$ & $x$ \\
\hline Granadilla & & & & & & & & & & & $x$ & $x$ \\
\hline Guamúchil & & & $x$ & & $x$ & $x$ & $x$ & $x$ & $x$ & & $x$ & $x$ \\
\hline Guayaba & $x$ & $x$ & $x$ & $x$ & $x$ & $x$ & $x$ & $x$ & $x$ & $x$ & $x$ & $x$ \\
\hline Guayaba de fresa & & & & & & & & & & & $x$ & \\
\hline Guayabo de piña & & & & & & & & & & & $x$ & \\
\hline Higo & $x$ & $x$ & $x$ & $x$ & $x$ & $x$ & $x$ & $x$ & $x$ & & $x$ & $x$ \\
\hline Jamaica & & & & & & $x$ & & & & & $x$ & $x$ \\
\hline Jengibre & & & & & & & & & & & $x$ & \\
\hline Jujube & & & & & & & & & & & & $x$ \\
\hline Lima dulce chichona & $x$ & & $x$ & $x$ & $x$ & $x$ & $x$ & $x$ & & & $x$ & $x$ \\
\hline
\end{tabular}




\begin{tabular}{|c|c|c|c|c|c|c|c|c|c|c|c|c|}
\hline Oasis Código & SB & SG & SI & GU & MU & LP & CU & SJ & LD & SLG & TS & SC \\
\hline Limón & $x$ & $x$ & $x$ & $x$ & $x$ & & $x$ & $x$ & $x$ & & $x$ & $x$ \\
\hline Limón Americana & $x$ & $x$ & $x$ & $x$ & $x$ & $x$ & $x$ & $x$ & $x$ & & $x$ & $x$ \\
\hline Limón base de injertos & & $x$ & $x$ & & $x$ & $x$ & $x$ & $x$ & $x$ & & $x$ & \\
\hline Limón real & & & $x$ & & $x$ & $x$ & $x$ & $x$ & $x$ & & $x$ & $x$ \\
\hline Litchi & & & & & & & & & & & $x$ & $x$ \\
\hline Macademia & & & & & & & & $x$ & & & $x$ & \\
\hline Maguey, mescal & & $x$ & $x$ & & $x$ & & & $x$ & $x$ & & $x$ & $x$ \\
\hline Mamey & & & & & & & & & & & $x$ & \\
\hline Mandarina & & $x$ & $x$ & & $x$ & $x$ & $x$ & $x$ & $x$ & & $x$ & $x$ \\
\hline Mango & $x$ & $x$ & $x$ & $x$ & $x$ & $x$ & $x$ & $x$ & $x$ & & $x$ & $x$ \\
\hline Mangostin & & & & & & & & & & & $x$ & \\
\hline Manzano & $x$ & $x$ & $x$ & & & $x$ & $x$ & $x$ & & & $x$ & $x$ \\
\hline Membrillo & $x$ & & & & & & & & & & & \\
\hline Mora blanca & & & $x$ & & $x$ & & & & & & & \\
\hline Mora negra & & $x$ & $x$ & & & & $x$ & & & & & \\
\hline Mora roja & & & $x$ & & & $x$ & $x$ & & & & & \\
\hline Mora, zarsamora & & & & & & & & & & & $x$ & \\
\hline Moringa & & & & & & & & & & & $x$ & \\
\hline Naranja amarga & $x$ & $x$ & $x$ & $x$ & $x$ & $x$ & $x$ & $x$ & $x$ & $x$ & $x$ & $x$ \\
\hline Naranja china & & & & & & & & & & & & $x$ \\
\hline Naranja dulce & & & & & $x$ & & $x$ & $x$ & & & $x$ & $x$ \\
\hline Naranja lima & $x$ & & $x$ & & $x$ & & $x$ & $x$ & $x$ & & $x$ & $x$ \\
\hline Níspero & & & & & & & $x$ & & & & $x$ & \\
\hline Nogal & & & & & & & & & & & $x$ & \\
\hline Nopal, tuna & $x$ & $x$ & $x$ & $x$ & $x$ & $x$ & $x$ & $x$ & & $x$ & $x$ & $x$ \\
\hline Nopalillo & & & $x$ & & $x$ & $x$ & $x$ & $x$ & & & $x$ & $x$ \\
\hline Olivo misionero & $x$ & $x$ & $x$ & $x$ & $x$ & $x$ & $x$ & $x$ & & & $x$ & $x$ \\
\hline Papaya & $x$ & $x$ & $x$ & & $x$ & $x$ & $x$ & $x$ & $x$ & & $x$ & $x$ \\
\hline Pecan & & & & & & & & & & & $x$ & \\
\hline Pera & & & $x$ & & & & & $x$ & & & $x$ & $x$ \\
\hline Pimienta & & & & & & & & & & & $x$ & \\
\hline Piña & & & & & & & & & & & $x$ & \\
\hline Plátano & $x$ & $x$ & $x$ & & $x$ & $x$ & $x$ & $x$ & $x$ & & $x$ & $x$ \\
\hline Pomarosa & & & & & & & & & & & $x$ & \\
\hline Pomelo/toronja & & & $x$ & $x$ & $x$ & $x$ & $x$ & $x$ & $x$ & & $x$ & $x$ \\
\hline Romero & & $x$ & $x$ & & & & $x$ & & & & $x$ & \\
\hline Ruda & & & & & & & & & & & & $x$ \\
\hline Tamarindo & & $x$ & $x$ & & $x$ & & $x$ & $x$ & $x$ & & $x$ & $x$ \\
\hline Tangerina, naranjito & & & & & & & & & & & $x$ & \\
\hline Té limón & & & & & & & & & & $x$ & $x$ & \\
\hline Tepeguaje & & $x$ & & & $x$ & $x$ & $x$ & $x$ & & & $x$ & $x$ \\
\hline
\end{tabular}




\begin{tabular}{|l|c|c|c|c|c|c|c|c|c|c|c|c|}
\hline Oasis Código & SB & SG & SI & GU & MU & LP & CU & SJ & LD & SLG & TS & SC \\
\hline Toronja & & & & & $\mathrm{x}$ & & $\mathrm{x}$ & & & & $\mathrm{x}$ & \\
\hline Uva misionera & $\mathrm{x}$ & $\mathrm{x}$ & $\mathrm{x}$ & $\mathrm{x}$ & $\mathrm{x}$ & $\mathrm{x}$ & $\mathrm{x}$ & $\mathrm{x}$ & $\mathrm{x}$ & & $\mathrm{x}$ & $\mathrm{x}$ \\
\hline Uvalma & & & & & & $\mathrm{x}$ & & & & & & \\
\hline Vainilla & & & & & & & & & & & $\mathrm{x}$ & \\
\hline Yaca & & & & & $\mathrm{x}$ & & & & & & $\mathrm{x}$ & \\
\hline Yerbabuena & & $\mathrm{x}$ & & & & & & $\mathrm{x}$ & & & $\mathrm{x}$ & \\
\hline Yuca & & & & & & & & & & & $\mathrm{x}$ & \\
\hline Zapote amarillo & & $\mathrm{x}$ & $\mathrm{x}$ & $\mathrm{x}$ & $\mathrm{x}$ & $\mathrm{x}$ & $\mathrm{x}$ & $\mathrm{x}$ & & & $\mathrm{x}$ & $\mathrm{x}$ \\
\hline Zapote negro/prieto & & & & & & & & & & & $\mathrm{x}$ & $\mathrm{x}$ \\
\hline
\end{tabular}

Fuente: Rouston, 2013.

Dos especies que se encuentran en las huertas, plantadas y cosechadas activamente como cultivos alimentarios, son nativas de la Península, se trata del cerezo nativo (Prunus serotina Ehrh. var. virens (Woot. y Standl.) McVaugh) y de la uvalama (Bumelia peninsularis Brandegee) (Delgadillo, 1998, León de la Luz et al, 1992). Veintiuna especies son nativas de México continental y/o de América Central y el Caribe, se trata de: pimienta (Pimenta dioica (L.) Merr.), anona (Annona reticulata $\mathrm{L}$.), guanábana (Annona muricata L.), anona (Annona squamosa L.), aguacate (Persea americana Mill.), agave (Agave spp.), plátano (Musa $\times$ paradisiaca), chiltepín (Capsicum annuum L. var. glabriusculum (Dunal) Heiser y Pickersgill), pomelo (Citrus xparadisi Macfad.), guayaba (Psidium guajava), mamey (Pouteria sapota (Jacq.) H.E. Moore \& Stearn), papaya (Carica papaya L.), ciruelo español/ciruela roja (Spondias purpurea L.), nopal (Opuntia ficus-indica), nopalillo (Opuntia cochenillifera (L.) Mill.), chico zapote (Manilkara zapota (L.) P. Royen), zapote negro (Diospyros digyna Jacq.), zapote blanco (Casimiroa edulis Llave \& Lex), tepeguaje
(Leucaena leucocephala (Lam.) de Wit) y vainilla (VaniIla planifolia Jacks) (Dunmire 2004; Janick y Paull 2008)7.

Esta revisión de especies es más amplia que los inventarios de 1771 y 1774, demostrando así que la diversidad agrícola de Los Comondú no sólo se ha mantenido, sino que ha aumentando, marcando la continuidad de colonialidad de saberes ambientales extendida en el tiempo contemporáneo, como revela la Tabla 5. La persistencia de especies misionales indica que los oasis misionales de la península, funcionan como reservas de la agrobiodiversidad. Como bien indica la Tabla 5, en el caso del Oasis de los Comondú, la continuidad pervivencia de las especies misionales ha supuesto una transformación antropogénica de larga escala para el agroecosistema, continuando la forma de colonialidad de los usos agrícolas bajo la permanencia de cultivos «importados» en la época de la colonización, subsumiendo otros saberes vinculados a la subsistencia, anclados en los grupos indígenas, erradicados de la centralidad de la formas de reproducción de la población sudcaliforniana.

Tabla 5. Especies perennes del oasis de Los Comondú

\begin{tabular}{|l|l|l|c|c|c|c|}
\hline Nombre & Nombre Científico & Familia & $\begin{array}{c}\text { Individuos en } \\
\text { total }\end{array}$ & $\begin{array}{c}\text { Especies en } \\
\text { total }\end{array}$ & $\begin{array}{c}\text { Individuos } \\
\text { misionales }\end{array}$ & $\begin{array}{c}\text { Especies } \\
\text { misionales }\end{array}$ \\
\hline Aguacate & Persea americana & Lauraceae & 343 & 1 & 343 & 1 \\
\hline Anona & Annona reticulata & Annonaceae & 23 & 1 & & 1 \\
\hline Caña de azúcar & $\begin{array}{l}\text { Saccharum } \\
\text { officinarum }\end{array}$ & Poaceae & $14.807 \mathrm{~m}^{2}$ & 1 & $14.807 \mathrm{~m}^{2}$ & 1 \\
\hline Chiltepín & Capsicum annuum & Solanaceae & 21 & 1 & & 1 \\
\hline Chirimoya & Annona cherimola & Annonaceae & 5 & 1 & 5 & 1 \\
\hline Ciruela anaranjada & Spondias mombin & Anacardiaceae & 1 & 1 & & \\
\hline Ciruela roja/amarilla & Spondias purpurea & Anacardiaceae & 50 & 1 & & \\
\hline $\begin{array}{l}\text { Cítricos: Calamondin } \\
\text { (naranjito) }\end{array}$ & $\begin{array}{l}\text { Citrofortunella } \\
\text { microcarpa }\end{array}$ & Rutaceae & 7 & 1 & & 1 \\
\hline $\begin{array}{l}\text { Cítricos: Lima dulce } \\
\text { chichona }\end{array}$ & Citrus limettioides & Rutaceae & 40 & 1 & 40 & \\
\hline
\end{tabular}




\begin{tabular}{|c|c|c|c|c|c|c|}
\hline Nombre & Nombre Científico & Familia & $\begin{array}{c}\text { Individuos en } \\
\text { total }\end{array}$ & $\begin{array}{c}\text { Especies en } \\
\text { total }\end{array}$ & $\begin{array}{l}\text { Individuos } \\
\text { misionales }\end{array}$ & $\begin{array}{l}\text { Especies } \\
\text { misionales }\end{array}$ \\
\hline Cítricos: Limón & Citrus aurantifolia & Rutaceae & 14 & 1 & 14 & 1 \\
\hline $\begin{array}{l}\text { Cítricos: Limón Ame- } \\
\text { ricano }\end{array}$ & Citrus limon & Rutaceae & 9 & 1 & & \\
\hline $\begin{array}{l}\text { Cítricos: Limón para } \\
\text { base de injertos }\end{array}$ & Citrus jambhiri & Rutaceae & 13 & 1 & & \\
\hline Cítricos: Limón real & Citrus híbrido & Rutaceae & 45 & 1 & & \\
\hline Cítricos: Mandarina & Citrus reticulata & Rutaceae & 60 & 1 & & \\
\hline Cítricos: Naranja ágria & Citrus aurantium & Rutaceae & 152 & 1 & 152 & 1 \\
\hline $\begin{array}{l}\text { Cítricos: } \\
\text { Naranja dulce }\end{array}$ & Citrus sinensis & Rutaceae & 311 & 1 & 311 & 1 \\
\hline Cítricos: Naranja-lima & Citrus sp. & Rutaceae & 20 & 1 & & \\
\hline $\begin{array}{l}\text { Cítricos: } \\
\text { Pomelo/toronja }\end{array}$ & Citrus maxima & Rutaceae & 30 & 1 & & \\
\hline Cítricos: Toronja & Citrus paradisi & Rutaceae & 8 & 1 & & \\
\hline Coco & Cocos nucifera & Arecaceae & 1 & 1 & 1 & 1 \\
\hline Dátil & Phoenix dactylifera & Arecaceae & 252 & 1 & 252 & 1 \\
\hline Durazno & Prunus persica & Rosaceae & 19 & 1 & 19 & 1 \\
\hline Granado & Punica granatum & Lythraceae & 53 & 1 & 53 & 1 \\
\hline Guamúchil & $\begin{array}{l}\text { Pithecellobium } \\
\text { dulce }\end{array}$ & Fabaceae & 8 & 1 & & \\
\hline Guayabo & Psidium guajava & Myrtaceae & 127 & 1 & 127 & 1 \\
\hline Higo & Ficus carica & Moraceae & 293 & 1 & 293 & 1 \\
\hline Mango & Mangifera indica & Anacardiaceae & 390 & 1 & & \\
\hline Manzano & Malus $\times$ domestica & Rosaceae & 5 & 1 & & \\
\hline Mora negra & Morus nigra & Moraceae & 1 & 1 & & \\
\hline Mora roja & Morus rubra & Moraceae & 1 & 1 & & \\
\hline Níspero & $\begin{array}{l}\text { Eriobotrya } \\
\text { japonica }\end{array}$ & Rosaceae & 20 & 1 & & \\
\hline Nopal & Opuntia spp. & Cactaceae & 6 & 1 & 6 & 1 \\
\hline Nopalillo & Nopalea spp. & Cactaceae & 100 & 1 & & \\
\hline Olivo misionero & Olea europaea & Oleaceae & 75 & 1 & 75 & 1 \\
\hline Papaya & Carica papaya & Caricaceae & 32 & 1 & & \\
\hline Plátano & Musa xparadisiaca & Musaceae & 188 & 1 & 188 & 1 \\
\hline Romero & $\begin{array}{l}\text { Rosmarinus } \\
\text { officinalis }\end{array}$ & Lamiaceae & 1 & 1 & & \\
\hline Tamarindo & Tamarindus indica & Fabaceae & 3 & 1 & 3 & 1 \\
\hline Tepeguaje & $\begin{array}{l}\text { Leucaena } \\
\text { leucocephala }\end{array}$ & Fabaceae & 51 & 1 & & \\
\hline Uva misionera & Vitis vinifera & Vitaceae & 4.851 & 1 & 4.851 & 1 \\
\hline Zapodilla & Manilkara zapota & Sapotaceae & 1 & 1 & & \\
\hline Zapote amarillo & Casimiroa edulis & Rutaceae & 19 & 1 & 19 & 1 \\
\hline Totales & & & 7.649 & 42 & 6.752 & 19 \\
\hline
\end{tabular}




\section{CONCLUSIONES}

Este artículo reflexiona sobre el valor histórico ambiental de los oasis sudcalifornianos en cuanto depósito de saberes ambientales mutados como transferencia desde Europa a América, y como resultado de la labor de experimentación e hibridación con los saberes de los pueblos nativos de Baja California Sur. Estos pueblos transitaron hacia la agricultura en pleno siglo XVIII con la llegada de los jesuitas que convirtieron las misiones en unidades de producción y consumo con la implantación de un sistema de cultivos altamente europeizado, particularmente con la irrupción de cultivos mediterráneos de la mano de la colonización de los jesuitas.

El establecimiento de misiones en la Antigua California fue un proceso difícil y lleno de contratiempos. Si sólo analizáramos el resultado de todo ese esfuerzo con respecto a la evangelización y transformación cultural de los neófitos indígenas podríamos llegar a la conclusión de que fue realizado en vano. Sin embargo, debemos reconocer que los establecimientos misionales, en su mayor parte, fueron la simiente de los posteriores poblados de la península; entre ellos Los Comondú.

De igual forma, una buena parte de las especies vegetales y animales traídas por los misioneros a estos territorios contribuyó a crear nuevos paisajes y a sostener a los pobladores que poco a poco fueron tomando la decisión de quedarse y tratar de prosperar.

\section{NOTAS}

1 Profesor Titular Departamento Historia Contemporánea Universidad de Granada, España. coordinador de la red Saberes Instituyentes SAB-INS (UGR-UABCS-UV-CIECO/UNAM-UAQ, UNICAUCA, OLD WESTBURY) este artículo es resultado de los proyectos de investigacion Mediterranean Mountainous Landscapes: An Historical Approach to Cultural Heritage Based on Traditional Agrosystem FP7 European Government, FP7-SS-2013-2 (2014-2018); Integración del Paisaje en los procesos de planificación. "Aplicación al caso andaluz». Proyectos de Excelencia, Junta de Andalucía, cód. RNM 5398 (2009-2013) y Cooperación, conflictos y equilibrios en el manejo colectivo de recursos naturales (siglos XV-XXI): Ministerio de ciencia e innovación (I+D+I) HAR2013-30732. Correo electrónico: aortegas@ugr.es

2 Así llamaban los misioneros a ciertos parajes en los que se reunía a grupos alejados del establecimiento principal para iniciar su evangelización. La mayor parte de estas Visitas consistían solamente en algunas chozas para guardar enseres, pero en diversas ocasiones se hacían algunas siembras o corrales para ganado, y en varios casos resultaron buenos parajes para la agricultura, por lo que pasaron a ser establecimientos principales, como fue el caso de Comondú.
Los cultivos de trigo y maíz, las palmas datileras, los frutales, la vid y los olivos, además de vacas, cabras y ovejas, constituyeron los principales ingredientes de este paisaje agrícola, que fueron construyendo los pobladores de San Miguel y San José de Comondú, los pueblos herederos de la extinta misión. Los operarios del sistema misional, además de realizar trabajos para adaptar cada especie que introducían, lograron acondicionar los espacios agrestes para crear huertos y sembradíos que habrían de perdurar mucho tiempo después de concluida su labor transformadora.

A esta perdurabilidad histórica pretende responder, por un lado, este artículo, evidenciando como los flujos de agrobiodiversidad han tenido una enorme adaptabilidad en agroecosistemas de enorme vulnerabilidad ambiental, los oasis sudcalifornianos. Por otro lado, este texto propone una mirada de la perspectiva decolonial que puede ser útil para los análisis de las continuidades y discontinuidades de los saberes ambientales, trazando la pervivencia e injerencia de estos saberes coloniales como actores protagonistas de procesos históricos de ecocidio y, sobre todo, del epistemicidio que supuso la llegada de los saberes europeos sobre las identidades territoriales preexistentes. El estudio se inserta igualmente dentro de los estudios sobre el intercambio colombino iniciados por Alfred Crosby. En este caso, analiza la introducción de cultivos y animales desde Europa con la transmisión no sólo de saberes sino que también de la agencia de los jesuitas en este proceso.

3 Carta del padre Jaime Bravo al marqués del Castillo de Aysa: Loreto, 10 de marzo 1742, citada en Del Río, 1984, p. 133.

4 Autos de visita: 1755, citado por Del Río, 2003, p. 108.

5 Carta del padre Juan María de Salvatierra al padre Juan de Ugarte: Real de Nuestra Señora de Loreto, 27, noviembre, 1697, en Del Río, 2003, p. 71.

6 Inventario de la misión de San José de Comondú hecho por el padre Fracisco Inama, diciembre 30, 1767, en Gobierno del Estado de Baja California Sur, Estadísticas históricas 1768-1879. Territorio Sur de la Baja California, La Paz, 2005, p. 45.

7 GRIN: Germplasm Resources Information Network [Online Database]. National Germplasm Resources Laboratory, Beltsville, Maryland, disponible en: http://www.ars-grin.gov [ consultado el 05/03/2011]; USDA (United States Department of Agriculture) Plants Database [online database], disponible en: http:// plants.usda.gov [ consultado el 01/11/12]. 


\section{BIBLIOGRAFÍA}

Altieri, M. A. y Merrick, L. C. (1987), "In situ conservation of crop genetic resources through maintenance of traditional farming systems", Economic Botany, 41 (1), pp. 86-96.

Baegert, J. J. (1989), Observations in Lower California. Berkeley, University of California Press, disponible en: http://ark.cdlib.org/ ark:/13030/ft5r29n9xv/

Barco, Miguel del. (1980), A Natural History of Baja California. Froylan Tiscareno (trad.), Miguel Leon-Portilla, (introd.), Los Angeles, Dawson's Bookshop.

Cariño Olvera, M. M. (1996), Historia de las Relaciones Hombre/Naturaleza en Baja California Sur, 1500-1940. La Paz, BCS: Centro de Investigaciones Biológicas del Noroeste, UABCS-SEP.

Cariño Olvera, M. M. (2007), “Exploraciones y descubrimientos 1533-1678". En: Cariño Olvera, M. M. et al (eds.), Sudcalifornia. De sus Orígenes a nuestros días. Instituto Sudcaliforniano de Cultura, Gobierno del Estado de BCS, UABCS, SIMAC, CONACYT, pp. 55-85.

Cariño Olvera, M. M. (2011), “La identidad oasiana,". En: Ortega Santos, Antonio y Ana Molina Aguado, (eds.), Oasis: Agua, Biodiversidad y Patrimonio, España, Editorial Atrio.

Cariño Olvera, M. M. y Lorella Castorena Davis. (eds.) (2007), Sudcalifornia: De Sus Orígenes a Nuestros Días, México, Universidad Autónoma de Baja California Sur.

Cariño Olvera, M. M.; Luis Alberto González; Erín Castro y Esteban Ojeda. (2000), "Vieja y Nuevas Concepciones de la Frontera: Aspectos teóricos y reflexiones sobre la historia sudcaliforniana". En: Estudios Fronterizos, 1 (2), pp. 143-183.

Cariño, M. M.; Antonio Ortega Santos; Aurora Breceda y Lorella Castorena Davis (eds.) (2013), Conocimiento, Valoración y Problemática del Oasis de Los Comondú. Barcelona, Icaria Editorial.

Castro-Gómez, S. (2011), “La Historia Natural en el orden clásico y geopolítico del saber". En: Montenegro Martínez, L. (ed.), Cultura y Naturaleza. Aproximaciones a propósito del bicentenario de la independencia de Colombia, Jardín Botánico de Bogotá, pp. 337-355.

Castro-Gómez, S. y Grosfoguel, R. (eds.) (2007), El giro decolonial. Reflexiones para una diversidad epistémica más allá del capitalismo global, Bogotá, Pontificia Universidad Javeriana-Instituto Pensar / Universidad Central / Siglo del Hombre.

Clavijero, Francisco Javier (1975), Historia de la Antigua o Baja California., Miguel Leon-Portilla, (ed.), México, Editorial Porrúa.

Crosby, Alfred W. (1999), Imperialismo Ecológico. La Expansión Biológica de Europa, 900-1900. Barcelona, Crítica.

Crosby, Harry W. (1994), Antigua California: Mission and Colony on the Peninsular Frontier, 1697-1768. Albuquerque, University of New Mexico Press.
De Mora, Fr. V. et al. (1774), California Antigua: Padrones y noticias de Estado de Las Misiones en el año del 1774.México, Archivo General de la Nacion (AGN), Provincias Internas (092)/ vol. 166. [consultado el 01.03.11].

Delgadillo, J. (1998), Florística y ecología del norte de Baja California. Ensenada, Universidad Autónoma de Baja California.

Dunmire, W. W. (2004), Gardens of New Spain: How Mediterranean Plants and Foods changed America. Austin, University of Texas Press.

Engelhardt, Z. (1908), The Missions and Missionaries of California, Vol. I. Lower California. San Francisco,The James H. Barry Company.

Escobar, A. (2011), "Epistemologías de la naturaleza y la colonialidad de la naturaleza. Variedades de realismo y constructivismo". En: Montenegro Martínez, L. (ed.), Cultura y Naturaleza. Aproximaciones a propósito del bicentenario de la independencia de Colombia, Jardín Botánico de Bogotá, pp. 49-75.

Farrés Delgado, Yasser (2013), Críticas Decoloniales a la Arquitectura, el Urbanismo y la Ordenación del Territorio. Hacia una territorialización de ambientes humanos en Cuba,Tesis Doctoral. Granada, Universidad.

Geubauer, J.; Luedeling, E.; Hammer, K.; Nagieb M. and Buerkert A. (2007), "Mountain oases in Northern Oman: an environment for evolution and in situ conservation of plant genetic resources", Genetic Resources and Crop Evolution, 54 (3), pp. 465-481.

GRIN: Germplasm Resources Information Network [Online Database]. National Germplasm Resources Laboratory, Beltsville, Maryland, disponible en: http://www.ars-grin.gov, [consultado el 05./03./2011].

Grosfoguel, R. (2007), “Descolonizando los universalismos occidentales: el pluri-versalismo transmoderno decolonial desde Aimé Césaire hasta los zapatistas". En: Castro-Gómez, S. y Grosfoguel, R. (eds.), El giro decolonial. Reflexiones para una diversidad epistémico más allá del capitalismo global, Bogotá, Pontificia Universidad Javeriana-Instituto Pensar / Universidad Central / Siglo del Hombre, pp. 63-78.

Grosfoguel, R. (2012), “Hacia la Descolonización de las Ciencias Sociales". En: Arribas Lozano, Alberto; Nayra García-González; Aurora Álvarez Veinguer y Antonio Ortega Santos (eds.), Tentativas, Contagios, Desbordes. Territorios del Pensamiento. Granada, Editorial UGR, pp. 73-107.

Gudynas, E. (2011), "Imágenes, ideas y conceptos sobre la naturaleza en América Latina”. En: Montenegro Martínez, L. (ed.) Cultura y Naturaleza. Aproximaciones a propósito del bicentenario de la independencia de Colombia. Jardín Botánico de Bogotá, pp. 267-295.

Hammer, K. and Teklu, Y. (2008), "Plant genetic resources: Selected issues from genetic erosion to genetic engineering," Journal of Agriculture and Rural Development in the Tropics and Subtropics, 109 (1), pp.15-50. 
Janick, J. and Paull R. E. (2008), The Encyclopedia of Fruits and Nuts. Wallingford, CAB International.

Lassépas, U. U. (1859), Historia de la Colonización de la Baja California. Decreto de 10 Marzo de 1857. México, Imprenta de Vicente García Torres.

León de la Luz, J. L. y Coria R. (eds.) (1992), Flora iconográfica de Baja California Sur. La Paz, Centro de Investigaciones Biológicas del Noroeste.

Lluch Belda, D. (1997), “Prólogo". En: Arriaga L. y Rodríguez Estrella R. (eds.), Los oasis de la Península de Baja California, La $\mathrm{Paz}$, Centro de Investigaciones Biológicas del Noroeste- SIMAC, pp. XI-XII.

Magnaghi, Alberto. (2011), El proyecto local. Hacia una conciencia del lugar. Barcelona, Edicions UPC.

Mathes, M. (1965), Californiana I. Documentos para la historia de la demarcación comercial de California, 1583-1632, en 2 vols. Madrid, José Porrúa Turanzas.

Mathes, M. (1970), Californiana II. Documentos para la historia de la explotación comercial de California, 1611-1679, en 2 vols. Madrid, José Porrúa Turanzas.

Maya, Y.; Coria, R. y Domínguez R. (1997), "Caracterización de los oasis", Cap. 2 . En: Arriaga L. y Rodríguez Estrella R. (eds.), Los oasis de la Península de Baja California, La Paz, Centro de Investigaciones Biológicas del Noroeste- SIMAC, pp. 5-25.

Mignolo, W. (2000a), "Border Thinking and the Colonial Difference". En: Local Histories/Global Desings: Coloniality, Subaltern Knowledges and Border Thinking. New Jersey: Princeton University Press, pp. 49-90.

Mignolo, W. (2000b), "Diferencia colonial y razón post-occidental". En Santiago Castro- Gómez (ed.). La reestructuración de las ciencias sociales en América Latina. Bogotá: Instituto Pensar, Pontificia Universidad Javeriana, pp. 3-28.

Mignolo, W. (2003), "Pensamiento fronterizo y diferencia colonial" En: Historias locales; diseños globales. Colonialidad, conocimientos subalternos y pensamiento fronterizo. Madrid, Akal.

Mukherjee, S. K. (1953), "The mango: Its botany, cultivation, uses and future improvement, especially as observed in India", Economic Botany,7 (2), pp. 130-162.

Nabhan, G. P. (2007), "Agrobiodiversity change in a Saharan Desert oasis, 1919-2006: Historic shifts in Tasiwit (Berber) and Bedouin crop inventories of Siwa, Egypt", Economic Botany, 61 (1), pp. 31-43.

Nabhan, G. P. (2012), Desert Terroir: Exploring the Unique Flavors and Sundry Places of the Borderlands. Austin, University of Texas Press.

Nabhan, G. P.; Garcia, J.; Routson, R.; Routson K. and Cariño Olvera, M. (2010), "Desert oases as genetic refugia of heritage crops: persistance of forgotten fruits in the mission orchards of Baja California, Mexico", International Journal of Biodiversity and Conservation, 2 (4), pp. 56-69.
Nabhan, G. P.; Rhea, A. M.; Reichhardt, K. L.; Mellink E. and Hutchinson C. F. (1982), "Papago influences on habitat and biotic diversity: Quitovac ethnoecology", Journal of Ethnobiology, vol. 2, pp. 124-143.

Ortega Santos, A. (2011), "Paisaje Agrario e Historia Ambiental. Una aproximación a Baja California hoy". En: Sorroche Cuerva, M.A. (ed.), El Patrimonio Cultural en las Misiones de Baja California, Granada, Ed. Atrio, pp. 227-266.

Ortega Santos, A. (2013), “Apogeo de la Sociedad Oasiana (19472010)". En: Cariño Olvera, M. et al. (eds.), Evocando al Edén. Conocimiento, Valoración y Problemática del Oasis de los Comondú, Barcelona, Ed. Icaria, pp. 285-316.

Quijano, A. (1991), "Colonialidad y modernidad/racionalidad", Perú indígena, 29, pp. 11-20.

Quijano, A. (1999), “Colonialidad del poder, cultura y conocimiento en América Latina". En: Santiago Castro-Gómez, Oscar Guardiola-Rivera y Carmen Millán de Benavides (eds.), Pensar (en) los intersticios. Teoría y práctica de la crítica poscolonial, Bogotá, Instituto Pensar, Pontificia Universidad Javeriana, pp. 99-109.

Quijano, Aníbal y Wallerstein, Immanuel. (1992), “Americanity as a Concept, or the Americas in the Modern World-System", International Social Science Journal, 44, pp. 549-557.

Quijano, Aníbal. (2000), “Colonialidad del poder, eurocentrismo y América Latina". En: Edgardo Lander (ed.), La colonialidad del saber: eurocentrismo y ciencias sociales. Perspectivas latinoamericanas, Buenos Aires, CLACSO, pp. 201-245.

Quijano, Aníbal. (2001), "Globalización, colonialidad y democracia”. En: Instituto de Altos Estudios Diplomáticos Pedro Gual (ed.), Tendencias básicas de nuestra época: globalización y democracia, Caracas, Instituto de Altos Estudios Diplomáticos Pedro Gual, pp. 25-61.

Ramón Laca, L. (2003), "The introduction of cultivated citrus to Europe via Northern Africa and the Iberian Peninsula", Economic Botany, 57 (4), pp. 502-514

Río Dueñas, Ignacio del (1974), "Población y misiones de Baja California en 1772. Un informe de fray Juan Ramos de Lora". En: Estudios de historia novohispana, vol. 5, Instituto de Investigaciones Históricas, México, Universidad Nacional Autónoma, pp. 241-271.

Río Dueñas, Ignacio del (1984), Conquista y aculturación en la California jesuítica. México, Universidad Nacional Autónoma de México.

Río Dueñas, Ignacio del (2003), El régimen jesuítico de la Antigua California. México, Universidad Nacional Autónoma.

Shreve, F. y Wiggins, L. (1964), Vegetation and flora of the Sonora Desert. San Francisco, Stanford University Press.

USDA (United States Department of Agriculture) Plants Database [online database], disponible en: http://plants.usda.gov, [consultado el 01/11/2012]. 
Venegas, M. (1757), Noticia de la California: y De Su Conquista Temporal, y Espiritual Hasta el Tiempo Presente. Madrid, En la imprenta de la viuda de M. Fernández.

Vernon, E. W. (2002), Las Misiones Antiguas: The Spanish Missions of Baja California, 1683-1855. Santa Barbara, CA, Viejo Press.

Wallerstein, I. (1984), El moderno sistema mundial II. El mercantilismo y la consolidación de la economía-mundo europea, 16001750. México, Siglo XXI Editores.

Wallerstein, I. (1998), El moderno sistema mundial III. La segunda era de gran expansión de la economía-mundo capitalista, 17301850. México, Siglo XXI Editores.
Wallerstein, I (2006), Análisis de sistemas-mundo. Una introducción. Madrid, Siglo XXI Editores.

Wehncke, E.W.; López-Medellín, X.; Rebman, J.; Wall, M. y Ezcurra E. (2010), Blue fan palm oases: new findings from the most remote populations, 53rd Annual Symposium IAVS. México, Ensenada, BC.

Wiggins I. L. (1980), Flora of Baja California. San Francisco, Stanford University Press.

Zizumbo-Villarreal, D. (1996), "History of coconut (Cocos nucifera L.) in Mexico: 1539-1810", Genetic Resources and Crop Evolution, vol. 43, pp. 505. 